\title{
ESTIMATING AND MAPPING CHLOROPHYLL-A CONCENTRATION OF PHEWA LAKE OF KASKI DISTRICT USING LANDSAT IMAGERY
}

\author{
N. Wagle ${ }^{1}$, R. Pote ${ }^{1}$, R. Shahi ${ }^{1}$, S. Lamsal ${ }^{1}$, S. Thapa ${ }^{1}$, T. D. Acharya ${ }^{2,3, *}$ \\ ${ }^{1}$ Dept. of Geomatics Engineering, Kathmandu University, Dhulikhel 45200, Nepal - (wagle1996, ranz.rz2722, rubcroyal, \\ lamsalshaligram, shangharsha.thapa)@ gmail.com \\ ${ }^{2}$ Dept. of Civil Engineering, Kangwon National University, Chuncheon 24341, Korea - tridevacharya @ kangwon.ac.kr \\ ${ }^{3}$ School of Geomatics and Urban Spatial Information, Beijing University of Civil Engineering and Architecture, Beijing 102616, \\ China
}

Commission V, WG V/7 and Commission IV , WG IV/6

KEY WORDS: Water quality, Chlorophyll-a, Landsat 8, Regression model, Phewa Lake

\begin{abstract}
:
Water is a major component in the living ecosystem. As water quality is degrading due to human intervention, continuous monitoring is necessary. One of the indicators is Chlorophyll-a (Chl-a) which indicates algal blooms which are often driven by eutrophication phenomena in freshwater. Lakes should be monitored for Chl-a because Chla-a is related to eutrophication phenomena which are an enrichment of water by nutrients salt. When the environment becomes enriched with nutrients the excessive growth can lead to the death of fish. In this study, the Remote Sensing (RS) and Geographic Information System (GIS) techniques were utilized to determine Chl-a concentration of Phewa Lake of Kaski district. We used Landsat 8 satellite imagery for estimation and mapping of the Chl-a concentration. In-situ measurements from different sample points were taken and used to form a regression model for Chl-a and its concentration over the water body was calculated. The preceding year's (2016) in situ measurement data of Chl-a concentration at a specific location were assessed with the one evaluated from the regression model thus produced for the succeeding year (2017) using Root Mean Square Error (RMSE) technique. As a result, we concluded that the estimation and mapping of Chl-a of a lake in Nepal can be done with the help of RS and GIS techniques.
\end{abstract}

\section{INTRODUCTION}

Water is one of the major components for the living creatures to survive. The water ecosystem, various types of resources valuable for the survival of the organisms are facing threat from a wide range of physical processes including land use/land cover change, pollution, global climate change as well as human interventions (Mushtaq and Pandey, 2013). Lakes and reservoirs store the part of these resources and satisfy both human requirements ranging from drinking water to recreation and environmental requirements to support high levels of biodiversity (Ismail et al., 2018). Due to the increased population growth, skyrocketing rate of industrial and urbanization sector as well as climate change, water quality is being deteriorated. These phenomena will continue to increase even more in the future, and many types of research have recognized declining water quality as one of the most crucial threats to society (Torbick et al., 2013). This led to a growing need for the monitoring of water quality parameters of lakes and reservoirs. Normally, water quality is evaluated in terms of its physical, chemical and biological parameters and recognizing the source of any possible pollution which might degrade water quality (Khattab and Merkel, 2013). Water quality monitoring using the primitive techniques dependent on in situ measurements followed by lab test of the collected water

Chlorophyll-a (Chl-a) is the major indicator of trophic state because it acts as a link between nutrient concentration, particularly phosphorus, and algal production. A eutrophication phenomenon is often related to Chl-a concentration (Han and Jordan, 2005). Eutrophication, determined by the algal bloom, is an enrichment of water by nutrient salts that causes structural changes to the ecosystem, which causes degradation in water quality and depletion of fish species (Liu et al., 2014). So, regular monitoring and mapping of the Chl-a parameter are necessary.

Regular monitoring and estimation of the Chl-a parameter are being limited in Nepal using only in-situ measurements followed by lab test of the collected water samples. This technique may provide accurate measurements of the quality parameter. However, this technique is usually not economic, time-consuming and is unable to provide a state of water quality in terms of real-time spatial and temporal extent. To combat the problem, satellite-based Remote Sensing (RS) is a powerful approach for routine assessment of spatial and temporal variations in lake water quality parameters and may offer a suitable method to integrate water quality data collected from traditional in situ measurements (Giardino et al., 2001). The advantages that can be observed by this technique are numerous, but the most substantial one being the Chl-a concentration estimation over the whole lake (i.e. larger spatial extent) without requiring the time consuming and expensive field survey for sampling.

In such context, RS and Geographic Information System (GIS) can be very useful tools in estimating and mapping the Chl-a concentration of lakes in Nepal. RS imagery provides frequent wide coverage of water bodies and GIS provides the platform

Corresponding author 
for efficient mapping and effective visualization. Landsat satellite has been the dominant source of satellite images for lake monitoring applications owing to its spatial resolution of 30m ground pixel size (Bartholomew et al., 2002). The costfree and four decades-long historical archives of Landsat data open up the opportunity for the researchers to utilize such product in order to estimate various phenomenon such as Chl-a concentration. Several studies showed the feasibility of Landsat data for promising estimation of water quality parameters over the lake (Guan, 2009; Ledesma et al., 2019; Liu et al., 2014).

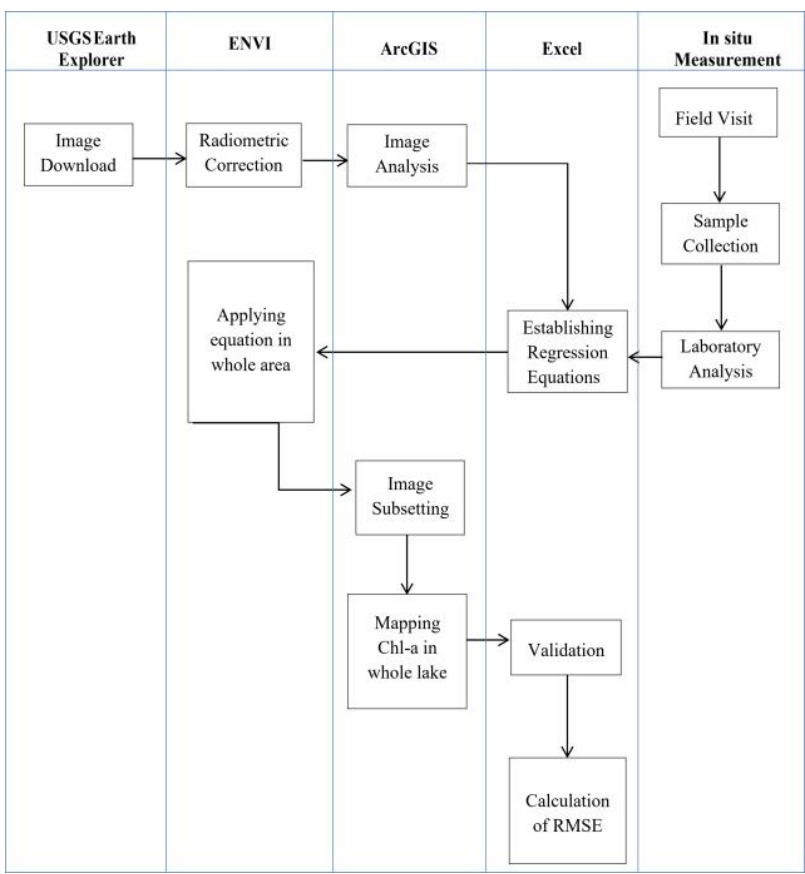

Figure 1. The workflow of the study

The major purpose of this study was to estimate and map the Chl-a concentration of Phewa Lake using RS and GIS techniques. For this purpose, Landsat 8 images were processed, analyzed and empirical relationships by regression between Chl-a parameter and spectral information were established. Finally, Root Mean Square Error (RMSE) was calculated to validate the result based on previous year's insitu data of a fixed location. Figure 1 shows the workflow adopted in this study.

\section{MATERIALS AND METHODS}

\subsection{Study Area}

Phewa Lake is the second largest lake, located in Pokhara, Nepal. It is a semi-natural freshwater lake fed by a stream and regulated by a dam to form a water reservoir (Shrestha and Janauer, 2001). It is located at an altitude of $742 \mathrm{~m}$ and covers an area of about 5.23 sq. km. (Rai, 2000). It has an average depth of about $8.6 \mathrm{~m}$ and a maximum depth of $24 \mathrm{~m}$ (Shrestha, 2003).

In addition to scenic value, Phewa Lake is a potential place for fisheries production. The livelihood of the Jalari community has been largely dependent on the aquaculture and fishing of this Lake (Wagle et al., 2007). It provides job opportunities, income and livelihood of fisher families. Regular estimation of Chl-a will help the farmers to maximize their production.

\subsection{Data}

Two types of data, satellite imagery and in-situ measurement for water quality, were used in this study.

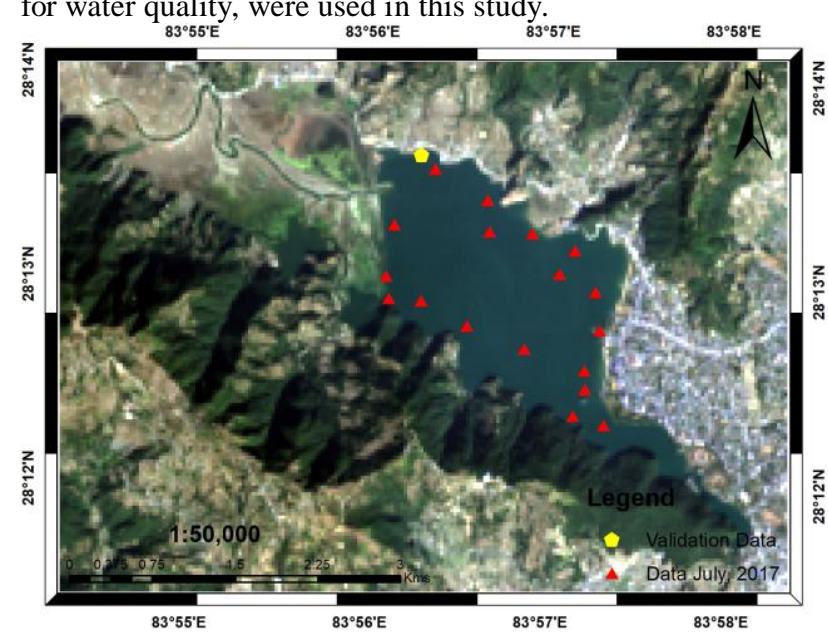

Figure 2. Location map of the study area

2.2.1 Satellite Imagery: Level $1 \mathrm{~T}$ processed images projected in WGS84 UTM zone 45N were downloaded from the USGS Earth Explorer which were, meaning that they have undergone systematic terrain calibration and geometric calibration. Images with less cloud cover were included in the analysis. Mostly water quality studies utilize only the visible and near-infrared (NIR) portions of the electromagnetic spectrum. Landsat 8 images from January 2016 to June 2017 were downloaded.

2.2.2 Water Quality Test: The water samples were collected from the area free of aquatic vegetation as such vegetation would falsify the true reflectance of the water. The pre-planning of field survey for the sample collected was planned on Google Earth imagery and their geolocation were recorded using handheld GPS from a boat. These water samples from different points were collected on narrow-necked bottles for measuring Chl-a.

\begin{tabular}{|c|c|c|c|}
\hline SN & Easting(m) & Northing(m) & Chl-a(mg/cu.m) \\
\hline 1 & 201112.57 & 3124570.665 & 6.8 \\
2 & 200970.22 & 3124208.712 & 4.1 \\
3 & 200426.54 & 3124405.891 & 7.4 \\
4 & 199904.49 & 3124614.532 & 5.2 \\
5 & 199490.63 & 3124841.762 & 3.8 \\
6 & 199196.00 & 3124864.193 & 3.6 \\
7 & 199173.39 & 3125065.563 & 6.3 \\
8 & 199250.43 & 3125531.549 & 3.8 \\
9 & 199497.07 & 3126164.642 & 3.9 \\
10 & 199622.58 & 3126034.000 & 5.2 \\
11 & 200096.57 & 3125753.999 & 5.1 \\
12 & 200111.62 & 3125466.403 & 4.6 \\
13 & 200503.15 & 3125453.087 & 4.3 \\
14 & 200886.00 & 3125294.122 & 4.1 \\
15 & 200748.05 & 3125083.932 & 5.5 \\
16 & 201071.78 & 3124917.922 & 5.3 \\
17 & 200976.78 & 3124035.931 & 5.8 \\
18 & 201145.63 & 3123712.3 & 6.2 \\
19 & 200866.87 & 3123795.968 & 5.9 \\
\hline
\end{tabular}

Table 1. Geolocation of sampled point with Chl-a value 
The water samples were collected in such a way that they have well-distributed i.e. 3 sample points per sq. km. (Zhang and Han, 2015)., sufficient enough to capture the variability of Chla concentration and at a certain distance away from the banks so as to avoid the possible effect of the solar radiation reflectance of the lake bottom. The lake was infested with water hyacinth near the shorelines. Thus, water samples were collected away from those shorelines avoiding water hyacinths. The collected samples were taken to a laboratory for in-situ measurement. Chl-a samples were obtained from $1000 \mathrm{ml}$ integrated sample bottles from which $300 \mathrm{ml}$ were filtered through GF/c (Whatman $47 \mathrm{~mm}$ ) filter paper. The Chl-a concentrations were determined according to methods by Carl J., (1967). The Chl-a concentrations from the laboratory analysis for the collected samples are represented in Table 1.

\subsection{Image processing}

To prepare the input satellite images for further processing, the following pre-processing steps were performed: radiometric calibration, atmospheric correction, image subsetting, and reflectance value extraction from $3 * 3$ reflectance window.

When the emitted or reflected electromagnetic energy is observed by a sensor, the observed energy does not coincide with the energy emitted or reflected from the same object observed from a short distance(Visual Information Solutions, 2009). This is due to the sun's azimuth and elevation, atmospheric conditions such as fog, sensor's response etc. which influence the observed energy. Therefore, in order to obtain the real irradiance or reflectance, those radiometric distortions must be corrected.

Each band of the satellite image was converted to top of atmosphere reflectance with sun angle correction using calibration coefficients provided in the metadata. Subsequently, the same image was subjected to atmospheric correction to avoid the possible effect of atmospheric conditions. Digital Number Image was converted to radiance value then surface reflectance using FLAASH in ENVI.

Next, the relationship between the in-situ measurements representing water quality parameter i.e. Chl-a in our case and mean reflectance values of satellite bands were established using the technique of regression analysis. The mean reflectance value was computed as the average reflectance values of a central pixel in a $3 * 3$ kernel so as to remove the probable uncertainty in GPS measured geolocation of sample points (Guan, 2009). The selection of a nine-pixel window is based upon the assumption that water is heterogeneous and often in flux due to seasonal, solar, and meteorological factors.

Since some sample window had less than nine viable pixels (due to clouds), ratio of the number of viable pixels was generated which was used to compute each sample, by band, so we could independently determine an acceptable minimum value threshold for each individual study by sorting results based on this field and eliminating any windows with a lower completion ratio than desired.

Pre-processed images were converted into various band combinations which will be used for regression. Mostly the combinations were done for red (B4), green (B3), and blue (B2) bands.

\subsection{Regression analysis}

Regression analysis is a statistical technique that is used to find the relationship between the variable(Fisher, 1922). Multiple regression models were used to define the relationship between remotely sensed mean reflectance data obtained from $3 * 3$ kernel earlier termed as the independent variable and the Chl-a concentration for the same point as the dependent variable. A large number of studies have examined single bands, band combinations including logarithmic, multiplicative, additive and band ratios as well (Ismail et al., 2018; Markogianni et al., 2017; Mushtaq and Ghosh, 2016; Wang and Yang, 2019) Markogianni et al. (2017) presented several types of band combinations to estimate mainly the Chla concentration in water bodies. Some of the band combinations used by the researcher were ratios of $\mathrm{B} 1 / \mathrm{B} 2$, $\mathrm{B} 2 / \mathrm{B} 3, \quad \mathrm{~B} 4 / \mathrm{B} 5$; simple arithmetic band combinations like $\mathrm{B} 1 * \mathrm{~B} 4, \quad \mathrm{~B} 2 * \mathrm{~B} 4, \quad \mathrm{~B} 3-\mathrm{B} 2,(\mathrm{~B} 2+\mathrm{B} 4) / 2, \mathrm{~B} 2 /(\mathrm{B} 1+\mathrm{B} 2+\mathrm{B} 3)$ and the logarithmic transformations like $\log (\mathrm{B} 1 / \mathrm{B} 2), \ln (\mathrm{B} 4 / \mathrm{B} 3)$ and many more. The variables used in the aforementioned band combinations represent individual bands of Landsat 8. An approach to use a similar type of band combinations were made; a portion of which is reflected in table 2 . The estimated relationships were followed by the computation of the coefficient of determination $\left(\mathrm{R}^{2}\right)$ between the mean reflectance values and Chl-a concentration parameters.

\begin{tabular}{|l|l|c|}
\hline Band combination & \multicolumn{1}{|c|}{ Regression equation } & $\mathrm{R}^{2}$ \\
\hline $\log \mathrm{B} 2 / \log \mathrm{B} 4$ & $\mathrm{y}=314.21 \mathrm{x}^{2}-547.58 \mathrm{x}+241.06$ & 0.212 \\
$\mathrm{~B} 2 * \log \mathrm{B} 4$ & $\mathrm{y}=149.42 \mathrm{x}^{2}+156.67 \mathrm{x}+12.386$ & 0.604 \\
$\mathrm{~B} 4 * \log \mathrm{B} 2$ & $\mathrm{y}=-1572.6 \mathrm{x}^{2}+48.732 \mathrm{x}+9.2711$ & -0.395 \\
$\log (\mathrm{B} 2 * \mathrm{~B} 4)$ & $\mathrm{y}=1.4045 \mathrm{x}^{2}-15.031 \mathrm{x}-28.138$ & 0.589 \\
$\log (\mathrm{B} 2 / \mathrm{B} 4)$ & $\mathrm{y}=120.8 \mathrm{x}^{2}-44.98 \mathrm{x}+7.1506$ & 0.129 \\
$\mathrm{~B} 4+\mathrm{B} 2$ & $\mathrm{y}=1156.1 \mathrm{x}^{2}-242.05 \mathrm{x}+14.767$ & 0.500 \\
B2 $2 \operatorname{logB4}$ & $\mathbf{y}=\mathbf{5 0 6 4 2 0} \mathrm{x}^{2}+\mathbf{3 8 6 4 . 5} \mathbf{+ 9 . 6 3 3}$ & $\mathbf{0 . 7 4 8}$ \\
$\log (\mathrm{B} 4 * \mathrm{~B} 3 * \mathrm{~B} 2)$ & $\mathrm{y}=1.1101 \mathrm{x}^{2}+6.5015+10.206$ & 0.628 \\
$(\mathrm{~B} 4+\mathrm{B} 2) /(\mathrm{B} 4-\mathrm{B} 2)$ & $\mathrm{y}=0.0007 \mathrm{x}^{2}-0.0948 \mathrm{x}+2.9484$ & 0.159 \\
\hline
\end{tabular}

Table 2. Regression equations and $\mathrm{R}^{2}$ values for various band combinations, where, B4=Red Band, B3=Green Band, B2=Blue Band

Furthermore, the established regression model was evaluated using the RMSE. The model with the maximum $\mathrm{R}^{2}$ and a minimum RMSE value (i.e. derived as a difference between the predicted values and the observed field values) indicates the better model and hence that particular model was chosen for the estimation of Chl-a concentration. The associated $\mathrm{R}^{2}$ and RMSE values of Chl-a are indicated in Table 2 and 3 respectively.

\subsection{Mapping and visualization}

Finally, the relationship with the band combinations resulting in the maximum $\mathrm{R}^{2}$ was then selected to apply for estimating and mapping the spatial variability of Chl-a concentration over the study area. The selected and validated model (i.e. maximum $\mathrm{R}^{2}$ and minimum RMSE) was henceforth applied to the entire study area showing the spatial as well as a temporal variation of Chl-a presented as a map on figure 4 .

\section{RESULTS AND DISCUSSION}

Different band combinations tested to generate regression equation along with their associated $\mathrm{R}^{2}$ value in order to find 
out the relation which best estimate the spatial variability of Chl-a concentration over the lake is mentioned in Table 2. Band combination of blue band and logarithmic function of the red band $\left(\mathrm{B} 2{ }^{2} \log \mathrm{B} 4\right)$ gave the highest value of $\mathrm{R}^{2}$ reflected as bold in the table. Figure 4 shows the scatterplot and regression line fitting the $\mathrm{B} 2^{2} \log \mathrm{B} 4$ band combination.

Spatial and temporal variations of Chl-a concentration over the lake were then mapped using the highlighted regression equation $\mathrm{y}=506420 \mathrm{x} 2+3864.5 \mathrm{x}+9.633$. The main reason to use this model was the highest coefficient of determination of 0.748 as well as the minimum RMSE value of $0.46 \mathrm{mg} / \mathrm{cu} . \mathrm{m}$
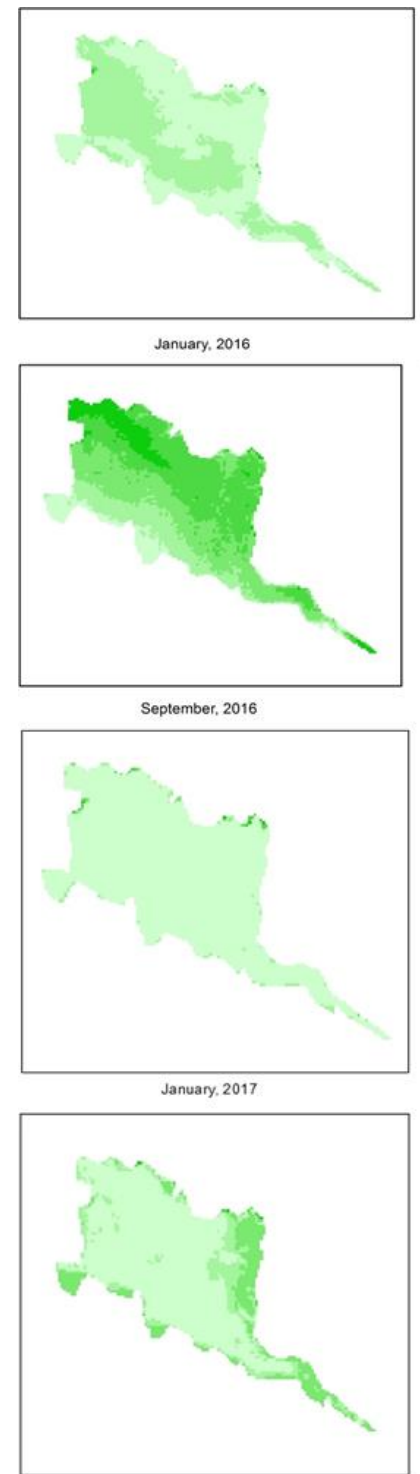

May. 2017

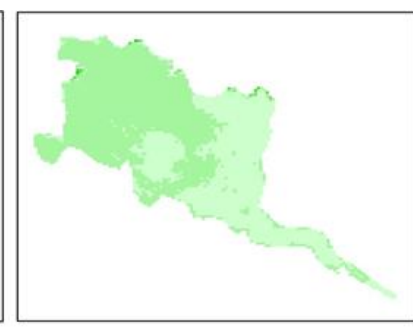

February, 2016
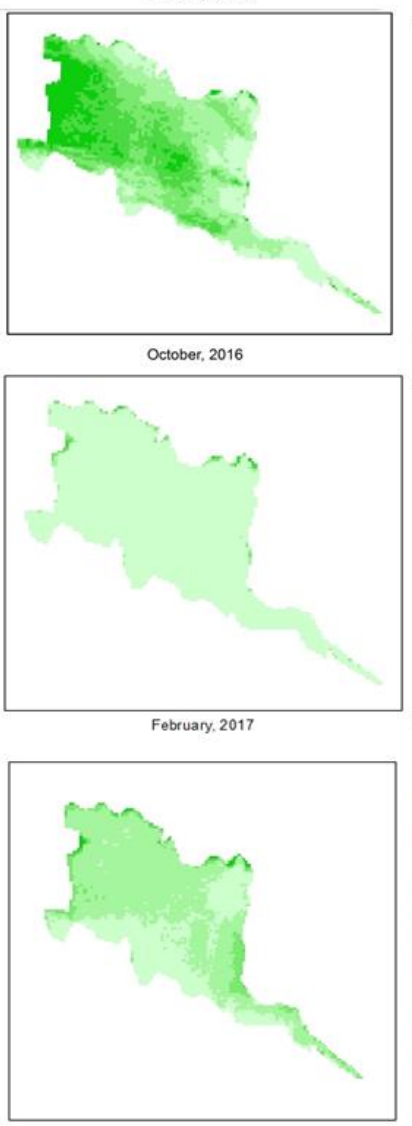

June. 2017

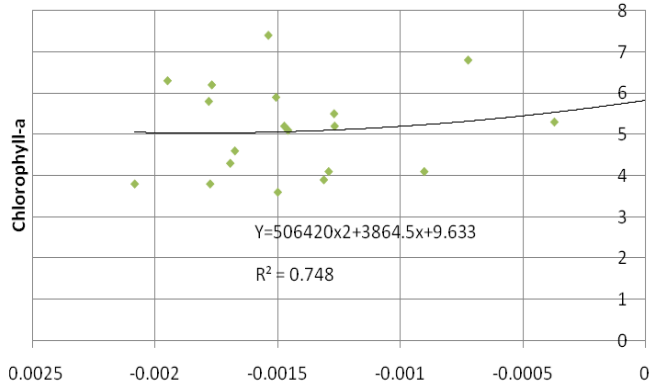

$\mathrm{B} 2 * \mathrm{~B} 2 * \log (\mathrm{B} 4)$

Figure 4 . The fitted regression line, its equation and $\mathrm{R}^{2}$

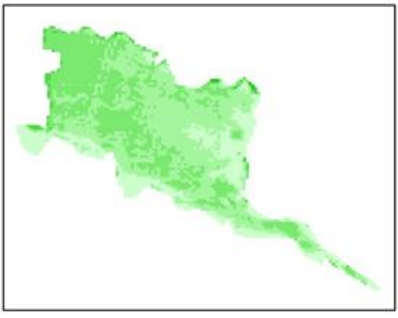

March, 2016

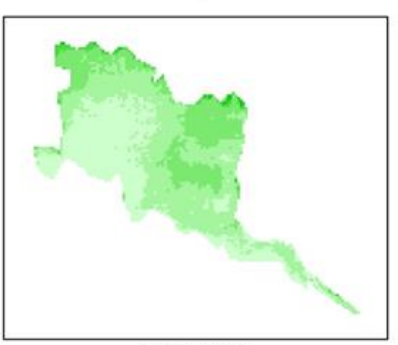

November, 2016

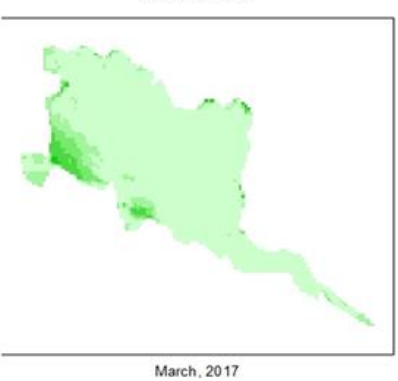

\section{Legend}

Chlorophyll (mg/cu.m)
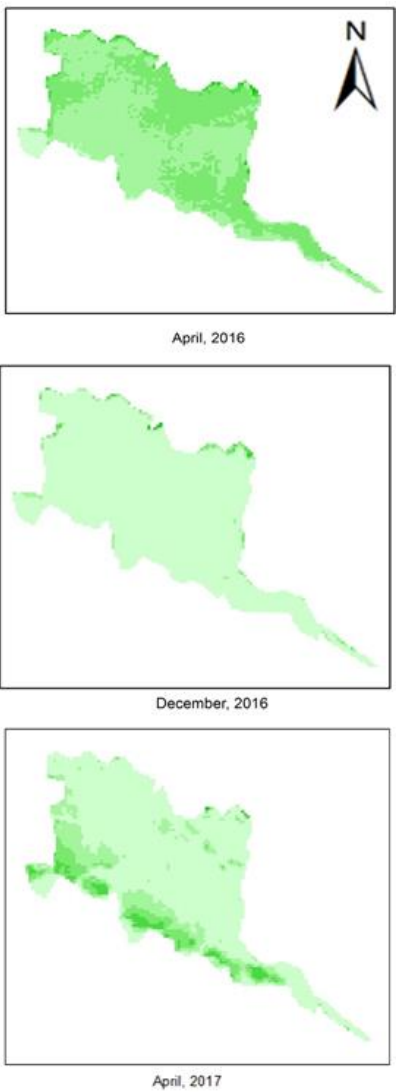

\section{Chlorophyll Map} Phewa Lake

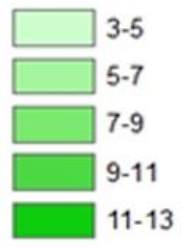

Figure 3. Chl-a maps of Phewa Lake using band combination and quadratic regression for different months associated with it.

Monthly Chl-a maps of Phewa Lake from the January 2016 to May 2017 were prepared. Higher cloud cover in the images of the rainy seasons like July and August made it impossible for the study to map the Chl-a concentration for those periods. Figure 4 shows all the maps produced for the Chl-a concentration of Phewa Lake. 
Empirical method was chosen for the analysis. Other methods could allow achieving a good precision because they are developed based on the accurate spectral measurement and the radiation transmission theory. However, it seemed to be difficult to develop complex models due to the broad bandwidth of OLI data.

The concentration of Chl-a frequently changes and fluctuate according to the weather and climate In the summer season, there is enough sunlight which results in a high value of Chl-a whereas in winter season there is less sunlight which results in less photosynthesis and consequently less Chl-a. When there is a shadow of the hills nearby lake there is a certain concentration of parameter and when there is no shadow there is a certain concentration of the parameter.

Looking at the Chl-a map, we can find that the concentration increases from April to July whereas decreases from September to February which indicated that there is fluctuation of Chl-a concentration due to seasonal changes. In the summer season and rainy season, there is a high concentration of Chl-a but in the winter season, there is less concentration of Chl-a. The data obtained has the RMSE of $0.458 \mathrm{mg} / \mathrm{cu} . \mathrm{m}$ for Phewa Lake.

\begin{tabular}{|c|l|c|c|}
\hline S.No. & \multicolumn{1}{|c|}{ Date } & $\begin{array}{c}\text { In Situ Chl-a } \\
\text { (mg/cu.m) }\end{array}$ & $\begin{array}{c}\text { Obtained Chl-a } \\
\text { (mg/cu.m) }\end{array}$ \\
\hline 1 & May, 2017 & 3.6 & 3.4 \\
2 & April, 2017 & 3.3 & 3.5 \\
3 & March, 2017 & 3.1 & 3.1 \\
4 & February, 2017 & 3.1 & 3.0 \\
5 & January,2017 & 3.2 & 3.4 \\
6 & December, 2016 & 3.0 & 3.1 \\
7 & November, 2016 & 3.7 & 3.9 \\
8 & October, 2016 & 5.4 & 5.2 \\
9 & September, 2016 & 11.1 & 9.1 \\
10 & April, 2016 & 5.1 & 5.7 \\
11 & March, 2016 & 4.7 & 4.9 \\
12 & February, 2016 & 3.2 & 3.0 \\
13 & January, 2016 & 3.4 & 3.7 \\
\hline \multicolumn{2}{|c|}{ RMSE $=0.457009 \mathrm{mg} / \mathrm{cu} . \mathrm{m}$} \\
\hline
\end{tabular}

Table 3. Monthly Chl-a concentration at $199497.066 \mathrm{~N}$ and

$3126164 \mathrm{E}$ along with the obtained value and RMSE for validation

Phytoplankton, algae and other floating aquatic plant populations can exhibit significant spatial and temporal variation The difference in the Chl-a concentration in the same month of the different year indicates that the growth of phytoplankton depends on the environmental condition and changes in time and space. The biggest influence on year-toyear differences in phytoplankton productivity is typical lake surface temperatures, wind patterns and, rainfall in the lake. Depending on rainfall, water flush from barrier gates, the concentration varies and dilution can cause phytoplankton's growth. Thus, linking field measurements of Chl-a concentrations and signatures captured by remote sensing techniques in moving waters is not straight forward.

The limitation of the study was that the in-situ measurement was not taken on the exact date of the image captured due to lack of time and resources. Small sample size was also another limitation on this study. Greater number of uniformly distributed samples could produce a better result.

\section{CONCLUSIONS}

In this study, RS and GIS techniques were used to estimate and map the Chl-a concentration of Phewa Lake by using Landsat imagery by means of a regression model. Multiple regression analysis helped to create the best-fit regression model with $\mathrm{R}^{2}=0.785$ which resulted out in generating reliable accuracy while assessing the efficiency of the model with in-situ measurement of certain fixed point with RMSE of 0.458 $\mathrm{mg} / \mathrm{cu} . \mathrm{m}$.

Based on the various techniques and satellite sensors as discussed, it is seen that RS satellite imageries data can be successfully utilized for mapping the spatial variability of water quality parameter i.e. Chl-a over the lake. The present study concludes the efficacy of those imageries for establishing a cost-effective method for routine monitoring of lakes. Routine observation of lake water quality using remote sensing may be considered by different organizations as an alternative method to field survey for recording and processing water quality information for various works including fisheries. For developing generalized water quality parameters models, numerous studies are to be carried out considering variations of these parameters in different seasons.

\section{ACKNOWLEDGEMENTS}

Our sincere gratitude goes to Chief Officer, Senior Scientist, Suresh Kumar Wagle, Fisheries Research Division, for offering us this chance and providing us with his support to do this project.

\section{REFERENCES}

Bartholomew, P., Grizzard, T.J., Wynne, R., 2002. Mapping and Modeling Chlorophyll-a Concentrations in the Lake Manassas Reservoir Using Landsat Thematic Mapper Satellite Imagery.

Carl J., L., 1967. Determination of Chlorophyll and PheoPigments: Spectrophotometric Equations. Limnol. Oceanogr. 12, 343-346.

Fisher, R.A., 1922. The Goodness of Fit of Regression Formulae, and the Distribution of Regression Coefficients. J. R. Stat. Soc. 85, 597. https://doi.org/10.2307/2341124

Giardino, C., Pepe, M., Brivio, P., Ghezzi, P., Zilioli, E., 2001. Detecting chlorophyll, Secchi disk depth and surface temperature in a sub-alpine lake using Landsat imagery. Sci. Total Environ. 268, 19-29. https://doi.org/10.1016/S00489697(00)00692-6

Guan, X., 2009. Monitoring Lake Simcoe Water Quality using Landsat TM Images.

Han, L., Jordan, K.J., 2005. Estimating and mapping chlorophyll- $a$ concentration in Pensacola Bay, Florida using Landsat ETM+ data. Int. J. Remote Sens. https://doi.org/10.1080/01431160500219182

Ismail, K., Arioua, A., Boudhar, A., Mohammed, H., Sabri, E., Ait Ouhamchich, K., Elhamdouni, D., Idrissi, E., Nouaim, W., 2018. Evaluating the potential of Sentinel-2 satellite images for 
water quality characterization of artificial reservoirs: The Bin El Ouidane Reservoir case study (Morocco). Meteorol. Hydrol. Water Manag. https://doi.org/10.26491/mhwm/95087

Khattab, M., Merkel, B., 2013. Application of Landsat 5 and Landsat 7 images data for water quality mapping in Mosul Dam Lake, Northern Iraq. Arab. J. Geosci. 7. https://doi.org/10.1007/s12517-013-1026-y

Ledesma, M.M., Bonansea, M., Ledesma, C.R., Rodríguez, C., Carreño, J., Pinotti, L., 2019. Estimation of chlorophyll-a concentration using Landsat 8 in the Cassaffousth reservoir. Water Supply. https://doi.org/10.2166/ws.2019.080

Liu, X., Fei, D., He, G., Liu, J., 2014. Use of PCA-RBF model for prediction of chlorophyll-a in Yuqiao Reservoir in the Haihe River Basin, China. Water Sci. Technol. Water Supply 14, 73-80. https://doi.org/10.2166/ws.2013.175

Markogianni, V., Kalivas, D., Petropoulos, G., Dimitriou, E., 2017. Analysis on the Feasibility of Landsat 8 Imagery for Water Quality Parameters Assessment in an Oligotrophic Mediterranean Lake. World Academy of Science, Engineering and Technology, International Journal of Environmental, Chemical, Ecological, Geological and Geophysical Engineering.

Mushtaq, F., Ghosh, M., 2016. Remote Estimation of Water Quality Parameters of Himalayan Lake (Kashmir) using Landsat 8 OLI Imagery. Geocarto Int. 32. https://doi.org/10.1080/10106049.2016.1140818

Mushtaq, F., Pandey, A., 2013. Assessment of land use/land cover dynamics vis-??-vis hydrometeorological variability in Wular Lake environs Kashmir Valley, India using multitemporal satellite data. Arab. J. Geosci. 7. https://doi.org/10.1007/s12517-013-1092-1

Rai, A.K., 2000. Evaluation of natural food for planktivorous fish in Lakes Phewa, Begnas, and Rupa in Pokhara Valley, Nepal. Limnology. https://doi.org/10.1007/s102010070014

Shrestha, P., 2003. Conservation and management of Phewa Lake ecosystem, Nepal. Aquatic Ecosystem Health and Management Society.

Shrestha, P., Janauer, G.A., 2001. Management of Aquatic Macrophyte Resource: A Case of Phewa Lake, Nepal. Environ. Agric. Biodiversity, Agric. Pollut. South Asia 99-107.

Torbick, N., Hession, S., Hagen, S., Wiangwang, N., Becker, B., Qi, J., 2013. Mapping inland lake water quality across the Lower Peninsula of Michigan using Landsat TM imagery. Int. J. Remote Sens. 34, 7607-7624. https://doi.org/10.1080/01431161.2013.822602

Visual Information Solutions, I., 2009. Getting Started with ENVI Restricted Rights Notice Limitation of Warranty Permission to Reproduce this Manual Export Control Information.

Wagle, S.K., Gurung, T. bahadur, Bista, J.D., Rai, A.K., 2007. age fish culture and fisheries for food security and livelihoods in mid hill lakes of Pokhara Valley, Nepal: post community based management adoption. Aquaculuture Asia Mag. 10.
Wang, X., Yang, W., 2019. Water quality monitoring and evaluation using remote-sensing techniques in China: A systematic review. Ecosyst. Heal. Sustain. 5, 47-56. https://doi.org/10.1080/20964129.2019.1571443

Zhang, C., Han, M., 2015. Mapping Chlorophyll-a Concentration in Laizhou Bay Using Landsat 8 OLI data. EProceedings 36th IAHR World Congr. 6. 